\title{
LEGISLAÇÃO BRASILEIRA E ACESSIBILIDADE FÍSICA NO ENSINO SUPERIOR: UMA ABORDAGEM (EX/IN)CLUSIVA?
}

\author{
Carolline Septimio \\ Genylton Odilon Rêgo da Rocha ${ }^{\text {ii }}$ \\ Geovana Mendonça Lunardi Mendesiii
}

Resumo: Fruto da pesquisa de mestrado defendida na Universidade Federal do Pará (UFPA), nosso artigo teve por objetivo esmiuçar como a legislação brasileira tem abordado a acessibilidade física nas instituições de ensino superior. De cunho qualitativo, a pesquisa foi desenvolvida a partir do levantamento da legislação nacional em vigor que versa sobre acessibilidade física no ensino superior. Para tal debate, tomamos por referencial teórico, entre outros pesquisadores, Carvalho (2012), Duarte e Cohen (2004; 2007) e Miranda (2011). Na investigação concluímos que a despeito dos avanços significativos da legislação brasileira no tocante ao tema, a acessibilidade vem sendo abordada de modo excludente, pois determina a construção, reforma e ampliação de espaços destinados aos Estudantes que possuem deficiências, o que denota uma abordagem exclusiva no uso dos espaços físicos e não garante o acesso e permanência de todas as pessoas.

Palavras-chave: Legislação brasileira. Acessibilidade física. Estudantes com deficiência. Ensino Superior.

\section{Brazilian legislation and physical accessibility in higher education: an (ex/in)clusive approach?}

\begin{abstract}
As a result of the master's thesis presented at the Universidade Federal do Pará (UFPA), our article aimed to analyze how Brazilian legislation has approached physical accessibility in higher education institutions. In a qualitative way, the research was developed based on the national legislation in force that deals with physical accessibility in higher education. For this debate, we took as reference, among other researchers, Carvalho (2012), Duarte and Cohen (2004; 2007) and Miranda (2011). In the work, we conclude that, in spite of significant advances in Brazilian legislation on this subject, accessibility has been approached in an exclusive way, since it determines the construction, remodeling and expansion of spaces for Students with disabilities, which denotes an exclusive approach in the use of physical spaces and does not guarantee the access and permanence of all people.
\end{abstract}

Keywords: Brazilian legislation. Physical accessibility. Students with disabilities. Higher education.

\section{Introdução}

Os espaços são experienciados de diversas maneiras e, na relação do sujeito com seu corpo e com outras pessoas, o espaço é pensado e construído a partir das necessidades biológicas e das relações sociais. O ser humano não constrói instintivamente, mas a partir de uma consciência de suas necessidades e experiências com o espaço.

A organização de uma cidade representa um modo de compreender a realidade e lembra 


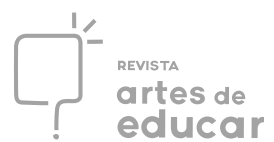

onde se situam os sujeitos, econômica e socialmente. Para as construções dos espaços parece prevalecer a ideia da existência do homem-padrão e a partir dele (sua altura, peso e medidas) teríamos um referencial. Desse modo, a estandardização do espaço arquitetônico, desenhado à luz da padronização humana, criaria seus próprios obstáculos físicos e sociais à participação plena das pessoas em diversas atividades comuns, tornando-os inacessíveis.

Quando pensamos em promover o acesso a instalações físicas, meios de transporte, mobiliário ou serviços, estamos pensando em situações do cotidiano que ofereçam benefícios a todos que as utilizam. O acesso aqui não é privilégio de um grupo de pessoas com/sem deficiência, mas premissa básica da vida em sociedade. Pensar em acessibilidade envolve todas as pessoas, sejam idosos, obesos, cardíacos, pessoas com dificuldades respiratórias, mulheres grávidas, ou seja, uma multiplicidade humana.

Com a expansão do ensino superior, a partir dos anos de 1930, o aumento de vagas nos cursos trouxe para essas instituições uma gama de estudantes negros, índios, com deficiência, entre outras minorias que antes não se faziam presentes nesses espaços. Entretanto, foi pelo ingresso de Estudantes com deficiência ${ }^{1}$ no ensino superior que esses espaços físicos começaram a ser questionados.

Para Mazzoni (2003) ao passo que se busca eliminar barreiras físicas para acesso de pessoas com limitação de deslocamento, as construções/reformas não podem dificultar a vida dos demais usuários. Isso nos fez pensar que cada elemento do espaço deve ser observado individual e coletivamente para que a facilidade de uns não se torne a barreira de outros, lembrando que a acessibilidade não é exclusivamente para Estudantes com deficiência.

Sabendo que o ensino superior deve ser um espaço inclusivo, nosso artigo partiu da seguinte problemática: como a legislação brasileira tem abordado a acessibilidade física nas instituições de ensino superior? Para tal análise, ancoramos nosso artigo em um referencial teórico de estudiosos do campo, como Carvalho (2012), Duarte e Cohen(2004; 2007) e Miranda (2011).

A partir dessa questão, apresentamos nesse artigo os principais resultados dessa investigação. Nosso texto divide-se em três momentos. No primeiro é traçado o percurso metodológico para desenvolvimento da investigação: documentos legais selecionados e aspectos a serem considerados. No segundo são apresentadas as discussões e análises da legislação nacional que versa sobre acessiblidade física no ensino superior. No terceiro expusemos algumas reflexões finais trazidas pelo debate da acessibilidade física no contexto da inclusão no ensino

\footnotetext{
${ }^{1}$ Utilizamos a inicial maiúscula nas palavras em que nos referirmos às Pessoas/Estudantes/Sujeitos com para evidenciar a importância da Pessoa sobre a deficiência.
} 
superior.

Esperamos que nossa pesquisa traga ao leitor uma reflexão acerca do tipo de abordagem que a legislação brasileira traz no âmbito da acessibilidade física no ensino superior em sua perspectiva (ex/in)clusiva.

\section{Percurso metodológico}

Partimos de um conceito de acessibilidade nesta pesquisa enquanto direito de todo cidadão e compreendemos que quando não há acesso surge a primeira barreira à participação da vida plena em sociedade. Sabemos que esse direito tem sido bandeira levantada por um grupo expressivo de Pessoas com deficiência e das que lutam pelos direitos dessas Pessoas.

Para nosso trajeto metodológico, fizemos o levantamento da legislação nacional em vigor publicada pelo governo federal que verse sobre acessibilidade física no ensino superior. Para tanto, selecionamos as publicações do site do Planalto da Presidência da República que concentra a legislação oficial atualizada sobre nosso tema de investigação.

Para Fávero (2001, p. 52) “o conjunto de normas jurídico-constitucionais constitui um campo aberto à realização de pesquisas sistemáticas, na área da educação". Portanto, a análise da legislação em vigor revela-nos um espaço profícuo ao debate acerca dos avanços e limitações que a educação vivencia, especialmente numa perspectiva de inclusão.

De cunho qualitativo, essa investigação entende que:

O conhecimento não se reduz a um rol de dados isolados, conectados por um teoria explicativa; o sujeito-observador é parte integrante do processo do conhecimento e interpreta os fenômenos, atribuindo-lhes um significado (CHIZZOTI, 2008, p. 79).

Para efeitos desse artigo, analisamos as seguintes publicações:

- Constituição da República Federativa do Brasil CF/88 que, como Lei máxima da nação, limita poderes e define direitos e deveres (BRASIL, 1988).

- Decreto 3.956/01 que promulga a Convenção Interamericana para a eliminação da discriminação contra pessoas portadoras de deficiência (BRASIL, 2001).

- Portaria 3.284/03 que dispõe sobre requisitos de acessibilidade para pessoas portadoras de deficiência física e sensorial (BRASIL, 2003).

- Decreto no 5296/04 que regulamenta as Leis no 10.048/00 e 10.098/00 (BRASIL, 2004).

- Decreto 6.949/09 que promulga a Convenção Internacional sobre os Direitos das Pessoas com Deficiência e seu protocolo facultativo (BRASIL, 2009). 
- Decreto 7.611/11 que dispõe sobre educação especial e o atendimento educacional especializado (BRASIL, 2011)

Nossa imersão nos textos oficiais não é meramente com objetivo de descrevê-los, uma vez que na pesquisa qualitativa o pesquisador não é mero relator passivo, mas observa percepções e concepções que embasam práticas e costumes, sendo o próprio pesquisador parte fundamental da investigação (CHIZZOTI, 2008).

A análise dos documentos foi feita seguindo a ordem cronológica de publicação. Destacamos ainda que os textos selecionados, em sua maioria, não apresentam a regulamentação voltada exclusivamente à acessibilidade física no ensino superior, contudo, escrevem acerca da acessibilidade física em edificações de uso público, o que compreende também as instituições educacionais.

\section{Discussão e análise da legislação nacional: uma abordagem (ex/in)clusiva?}

O último censo demográfico do Instituto Brasileiro de Geografia e Estatística- (IBGE), realizado em 2010, aponta que dos 190.755 .799 de habitantes no país, 45.623 .910 apresentam alguma deficiência, o que representa 23,9\% da população (IBGE, 2017). Trilhando os últimos relatórios técnicos do Instituto Nacional de Estudos e Pesquisas Educacionais Anísio Teixeira(INEP), observamos que dados mais recentes, referentes ao ano de 2015, apontam que dos 8.027.297 dos estudantes matriculados em cursos de graduação, somente 1.150.067 concluem os cursos. Do total de matrículas no país, 37.927 são estudantes com algum tipo de deficiência (INEP, 2017).

Mesmo abrigado na legislação nacional, o direito do Estudante com deficiência ao ensino superior parece-nos caminhar a passos tímidos. A inclusão nas instituições de ensino públicas é dever do Estado e direito garantido por lei.

Traçando um breve histórico da acessibilidade no Brasil, Santos Filho (2010) escreve que esse tema só passou a ter visibilidade no país na década de 1980, quando o movimento de Pessoas com deficiência lutava por garantias de acesso e a Constituição Federal respaldava a acessibilidade em edificações e transportes.

Após a regulamentação constitucional dando respaldo à acessibilidade, muitas ações foram impetradas na justiça visando garantir o direito das Pessoas com deficiência ao uso do espaço público, o que resultou no ganho de causa em uma ação importante contra a companhia de metrô no estado de São Paulo. Dessa forma, houve a necessidade de diversos profissionais da companhia de metrô e de secretarias do estado colaborarem para a construção de normas de 
acessibilidade, o que desaguou na elaboração da Norma Brasileira Registrada NBR 9050 de 1994 (SANTOS FILHO, 2010).

Nos anos 2000, surge o Comitê Brasileiro de Acessibilidade da Associação Brasileira de Normas Técnicas- (ABNT)- (CB-40) o qual fomentou ainda mais o debate acerca do acesso de Pessoas com deficiência aos espaços, mobiliário, equipamentos urbanos e meios de transporte. De acordo com Santos Filho (2010), a NBR 9050 (ABNT, 2004) trouxe grandes avanços no campo da acessibilidade, figurando o Brasil como um país privilegiado em termos de normas. Por outro lado, o autor escreve "Infelizmente, não ocorreu ainda de forma generalizada a materialização dessas normas em nossa realidade como acessibilidade ao meio em geral”. (SANTOS FILHO, p. 42, 2010)

Como enfatiza Leite (2007), a NBR 9050 apresenta soluções para remoção de barreiras e projetos novos livre de obstáculos desde a concepção. A autora afirma que esta norma já atendia aos preceitos do desenho universal, entretanto, lembra que as normas técnicas não têm força de lei e sua efetividade dá-se no momento em que decretos e leis passam a regulamentá-la.

Não nos furtando da importância da Norma supracitada, nesse artigo não nos detivemos na análise da NBR 9050 (e suas alterações) pois, como destacamos, não possui força de lei e nosso foco de discussão está na legislação nacional que aborda a acessibilidade física no âmbito da educação de nível superior.

Analisando a legislação brasileira no tocante à acessibilidade física, esmiuçamos alguns textos essenciais ao debate, quais são: Constituição Federal CF/88; Decreto 3.956/01; Portaria 3.284/03; Decreto $n^{\circ} 5296 / 04$ que regulamenta as Leis $n^{\circ} 10.048 / 00$ e 10.098/00; Decreto 6.949/09; e Decreto 7.611/11. Passemos a discuti-las.

A Constituição da República Federativa do Brasil CF/88 (BRASIL, 1988) que, como lei máxima da nação, limita poderes e define direitos e deveres, em seu art. $227 \S 1^{\circ}$ - II afirma que é dever da família, da sociedade e do Estado assegurar o direito à educação, repudiando toda forma de negligência e discriminação. Diz também que o Estado obedecerá ao preceito de facilitar o "acesso aos bens e serviços coletivos, com a eliminação de preconceitos e obstáculos arquitetônicos" (BRASIL, 1988).

Ainda no art. $227 \S 2^{\circ}$, alínea "c", determina que "A lei disporá sobre normas de construção dos logradouros e dos edifícios de uso público”. (BRASIL, 1988). O art. 244 também retoma a importância da adaptação dos edifícios de uso público, logradouros e dos veículos de transporte coletivo a fim de garantir acesso adequado às Pessoas com deficiência. Nesse sentido, entendemos que as instituições de ensino superior, enquanto espaço de uso público, devem garantir o acesso às suas dependências, eliminando barreiras físicas. 
No que tange à eliminação de obstáculos arquitetônicos, o art. 23 da Constituição outorga esta responsabilidade tanto à União quanto Estados e Municípios. Com relação à edição de normas gerais, compete à União a responsabilidade legislativa e aos estados e municípios a competência suplementar acerca da proteção e integração social das Pessoas com deficiência, conforme artigo 24 da Constituição Federal.

Sabemos que, numa perpectiva social, a condição socioambiental pode produzir uma experiência de deficiência:

Se as condições socioeconômicas e culturais não contemplarem a diversidade humana, inúmeras pessoas vão exteriorizar incapacidades. Estas se objetivam muito menos em função das limitações e muito mais em termos dos ajustes requeridos da sociedade (CARVALHO, 2012, p. 36).

Na mesma vereda, Diniz (2012) destaca que:

Uma pessoa pode ter lesões sem experimentar limitações de capacidade, como é o caso de alguém com cicatrizes de queimadura na face. Por outro lado, uma pessoa pode ter apenas expectativas de lesões, e já experimentar limitações de desempenho e restrições de participação (DINIZ, 2012, p. 51).

Percebemos que os entraves que dificultam a vida das Pessoas com deficiência também promovem a exclusão destas e de outras pessoas que não se enquadrem no "homem-padrão". Portanto, o modelo social nos interessa porque induz à reestruturação da sociedade, reflexão e ação em busca da inclusão:

Quando a diversidade humana é desconsiderada ou banalizada, as condições ambientais colocam as pessoas em situação de deficiência como incapacitadas, muito menos por suas características pessoais e, muito mais, pelas barreiras de toda a ordem com que elas se deparam (CARVALHO, 2012, p. 35).

Sabemos que as condições sociais é que se encontram incapazes de promover a real interação entre as pessoas, oportunizando experiências, equiparando oportunidades. Essas experiências precisam ser oportunizadas em espaços de interação com o outro, nos quais se aprenda, experiencie e realize. É nesse coletivo que as pessoas com e sem deficiência realizamse uns com os outros.

Analisando o texto da Constituição, observamos que o esforço está no sentido de adaptar os espaços, mas não universalizá-los. A ideia de espaços construídos para todas as pessoas e da eliminação de barreiras para uso de qualquer cidadão não parece presente no texto. Mais ainda: a Lei trata da necessidade de adaptação para uso das Pessoas com deficiência, ou seja, destinadas a esse público. 
Nessa mesma seara encontra-se o Decreto 3.956/01 (BRASIL, 2001) o qual promulga a Convenção Interamericana para a eliminação da discriminação contra pessoas portadoras de deficiência. No documento, há explícita afirmação de que a deficiência não deve ser elemento que dificulte/impossibilite o acesso aos mesmos direitos que os demais cidadãos.

Em seu art. $1^{\circ}$ (BRASIL, 2001) define-se o termo discriminação, enfatizando palavras como "exclusão", "restrição baseada na deficiência", "antecedente ou consequência de deficiência" que impeçam ou anulem os direitos das Pessoas com deficiência e suas liberdades. Trazemos à baila que o não acesso ao ensino superior constitui-se como forma de exclusão baseada/antecedente/precedente/iminente na/à deficiência, ou seja, como forma de discriminação que impede o exercício dos mesmos direitos que outras pessoas.

No art. $3^{\circ}$ (BRASIL, 2001) entre as responsabilidades dos Estados Parte está a de caráter educacional que visa à integração da Pessoa com deficiência à sociedade. $\mathrm{O}$ texto cita medidas de acessibilidade física em edifícios, com a eliminação de obstáculos arquitetônicos, de modo a facilitar o acesso de Pessoas com deficiência.

No Dicionário da Língua Portuguesa, Ferreira (2001, p. 10) escreve que a palavra acessível tem significado “ De acesso fácil (coisa ou pessoa); Inteligível, compreensível” o que nos remete à possibilidade de condições ambientais de informação, deslocamento, uso e organização de atividades que permitam as relações entre as pessoas e o espaço em que vivem.

O conceito de acessibilidade é entendido por Fortuna (2009, p. 15) de modo que:

Acessibilidade é a resposta física que passa pelas seguintes questões “ “ Como posso chegar até o prédio X?' ' Como entrar e me movimentar dentro daquele prédio Y?' ‘ Como me movimentar entre pisos e entrar nos cômodos?' 'Como utilizar as instalações do banheiro?' 'Como sentar no ônibus, sem a observância da lei dos obesos?' 'Como pagar os impostos no banco em fila única, mesmo sendo paraplégico?' ' Sou cego, como me locomover neste quarteirão?', entre outras ".

Tratamos de uma acessibilidade em linhas gerais, que perpassa o acesso físico, pedagógico, comunicacional, entre outras formas de oportunizar a interação entre os sujeitos. Entretanto, para efeitos desse estudo, precisamos nos deter à acessibilidade física enquanto conjunto de ações que visam garantir com segurança e autonomia o acesso, compreensão e circulação de todas as pessoas, inclusive aquelas com dificuldades de locomoção, a espaços físicos de edificações de uso público e coletivo.

O Decreto apresenta avanços em relação aos direitos das Pessoas com deficiência, porém, ainda adota uma perspectiva de exclusividade no uso de alguns espaços quando entende que devem ser destinados para as Pessoas com deficiência. 
Partimos do princípio de que os ambientes destinados a Pessoas com deficiência são estigmatizantes e carregam o sentido de que aquilo é destinado a "certo tipo de pessoa", o que não os torna inclusivos. Como destaca Martins (2007, p. 201) “A sociedade, portanto, por diversas razões e de várias formas, separa os 'iguais' dos 'diferentes', marca e estigmatiza os considerados 'diferentes'.

Com respeito a essa ideia, Duarte e Cohen (2004) afirmam que os espaços não acessíveis são atores de um apartheid silencioso, o que traduz uma barreira de relacionamentos. Por mais que a sociedade apresente um discurso que condene a exclusão social, ela mesma cria espaços que contradizem o que apregoa.

Adotando uma perspectiva inclusiva, entendemos o coletivo humano, cheio de necessidades específicas e desiguais, de direitos de dessemelhança. Essa igualdade de direitos por meio do acesso físico torna-se essencial quando sabemos da efemeridade da condição de “normais", lembrando que "Todos nós, de algum modo e segundo nossas próprias capacidades funcionais ou mentais, deparamo-nos com barreiras relacionadas ao movimento, às comunicações e ao alcance de compreensão de mensagens, instruções ou instrumentos" (DUARTE; COHEN, 2007, p. 155).

Na esteira desse debate, a Portaria 3.284 (BRASIL, 2003) versa a respeito dos requisitos de acessibilidade para Pessoas com deficiência física e sensorial, considerando necessidades básicas de acesso, mobilidade e utilização de equipamentos.

Nos arts. $1^{\circ}$ e $2^{\circ}$, a Portaria (BRASIL, 2003) determina que instrumentos que avaliem as IES levem em conta requisitos de acessibilidade de acordo com a NBR 9050. Os requisitos de acessibilidade foram categorizados por deficiências, entre física, visual e auditiva.

Com relação à deficiência física, a Portaria prevê: eliminação de barreiras arquitetônicas, reserva de vagas em estacionamentos; construção de rampas com corrimãos ou de elevadores; "adaptação" de banheiros, lavabos, bebedouros e telefones públicos. Quanto às Pessoas com deficiência visual e auditiva, a Portaria não prevê mudanças na estrutura física; quanto às alterações didático-pedagógicas, somente mediante solicitação e permanência do estudante com deficiência nas Instituições de Ensino Superior- (IES).

Notamos que a acessibilidade na Portaria 3.284 (BRASIL, 2003) aparece destituída dos princípios do desenho universal. As "adaptações" citadas no documento são destinadas especificamente a um grupo de Estudantes com deficiência. $\mathrm{O}$ texto desconsidera a possibilidade de que as benfeitorias arquitetônicas atinjam a todos os estudantes, independentemente de terem deficiências.

Observando Pessoas com limitações de locomoção, Mazzoni (2003, p. 94 e 95) escreve 
que "as barreiras arquitetônicas e urbanísticas são os principais obstáculos a serem superados no espaço físico e se defrontam também com situações de pseudo-acessibilidade, nas quais, aparentemente, tentou-se resolver o problema, mas de forma insatisfatória”. A chamada pseudoacessibilidade tem sido muito comum em edifícios, seja por construções de rampas ou instalação de corrimãos, quando a obra passa a ser considerada "acessível".

Para isto, faz-se necessário identificar os diferentes elementos que podem dificultar ou impedir a percepção, circulação, compreensão ou apropriação dos espaços e atividades por parte dos usuários, bem como obstáculos de ordem social e psicológica que impedem seu uso efetivo (DISCHINGER; ELY; PADARATZ, 2005, p. 04)

O espaço apreendido por uma pessoa que se desloca com cadeira de rodas não é o mesmo daquele que utiliza muletas. Portanto os espaços são apreendidos individualmente e a relação de cada sujeito no mesmo espaço precisa ser analisada sob diversos aspectos.

Consideramos que o referencial de homem-padrão para o qual os espaços públicos e privados são pensados precisa ser questionado pois é excludente, segregador e discriminatório, pois não contempla a todos, inclusive aqueles com deficiência. Todavia, não acreditamos que estamos espaços destinados à Pessoa com deficiência, como faz a Portaria quando regulamenta alterações para Pessoas com deficiência física e sensorial nas IES, seja a saída para um ensino superior inclusivo.

Sabemos que "Há organizações sociais pouco sensíveis à diversidade humana e que cultuam a homogeneidade entre seus membros, estigmatizando e discriminando os que fogem aos padrões estabelecidos" (CARVALHO, 2012, p. 34). Portanto, políticas públicas precisam ser inspiradas no modelo social de deficiência estabelecendo diretrizes na busca por um ambientes sociais livres de barreiras.

Estas devem ser entendidas como qualquer entrave ou obstáculo que limite ou impeça o acesso, a liberdade de movimentos e a circulação com segurança das pessoas. Barreiras tanto podem ser arquitetônicas (urbanísticas e na edificação), nas comunicações, como decorrentes de atitudes de rejeição ou de negação das pessoas em situação de deficiência ( CARVALHO, 2012, p. 37).

Mais uma vez apontamos que apesar do progresso contido na Portaria ao regulamentar alterações nas IES para promoção da acessibilidade física, não podemos nos furtar de que são as condições sociais que impossibilitam/dificultam a livre circulação e uso dos espaços por todas as pessoas e não as limitações que alguns possam ter. Se modificações são pensadas apenas para Pessoas com deficiência, podemos voltar à premissa errônea de que são esses Sujeitos que necessitam de estruturas exclusivas e não a sociedade que necessita repensar seu ideário de 
homogeneidade e perfeição.

Contribuindo para o campo em discussão, o Decreto no 5296 (BRASIL, 2004) regulamenta duas Leis: a de $\mathrm{n}^{\mathrm{0}} 10.048$, que institui a prioridade de atendimento, e a Lei 10.098, a qual discorre sobre a promoção de acessibilidade. O documento inicia explicando que as barreiras seriam "qualquer entrave ou obstáculo que limite ou impeça o acesso, a liberdade de movimento, a circulação com segurança e a possibilidade de as pessoas se comunicarem ou terem acesso à informação".

As barreiras são classificadas no documento em quatro formas: urbanísticas, de edificações, nos transportes e nas comunicações e informações. Dentre as barreiras, detivemonos nas geradas em edificações

As barreiras nas edificações são aquelas situadas no entorno e interior de edificações de uso público e coletivo e de uso privado multifamiliar. As edificações de uso público são administradas por entidades da administração pública, direta ou indireta, ou empresas prestadoras de serviços públicos, destinadas à população em geral. Edificações de uso coletivo são destinadas a diversas atividades, entre elas, as educativas. Ou seja, edificações de uso público e coletivo compreendem, entre outras, as IES.

No art. 10 fica dito que os princípios do desenho universal devem nortear a construção de projetos arquitetônicos, referendando-se nas normas da ABNT. Ainda no art. $10, \S 1^{\circ}$ fica prevista a inserção do desenho universal como conteúdo das diretrizes curriculares dos cursos tecnológicos e superiores de engenharia, arquitetura e correlatos. No $\S 2^{\circ}$ ganham destaque os programas e linhas de pesquisa que financiados pelo poder público devem incluir o desenho universal como eixo temático.

No art.11 institui- se que construções, reformas ou ampliação a edifícios que sejam ou venham a ser de uso público ou coletivo, devem ser acessíveis a Pessoas com deficiência. Para tanto, o texto prevê a fiscalização sobre os profissionais responsáveis, como também a aprovação, licenciamento e emissão de certificado de conclusão da obra, mediante atendimento às normas de acessibilidade previstas em Lei. A estas obras, é exigido o "Símbolo Internacional de Acesso" como instrumento que assegura um espaço livre de barreiras. O art. 24 afirma que:

Os estabelecimentos de ensino de qualquer nível, etapa ou modalidade, públicos ou privados, proporcionarão condições de acesso e utilização de todos os seus ambientes ou compartimentos para pessoas portadoras de deficiência ou com mobilidade reduzida, inclusive salas de aula, bibliotecas, auditórios, ginásios e instalações desportivas, laboratórios, áreas de lazer e sanitários (BRASIL, 2004).

Fica evidente que as universidades estão entre os estabelecimentos que devem 
proporcionar acessibilidade em todos os seus ambientes e compartimentos. Com relação à autorização de funcionamento, abertura ou renovação de curso, fica consignada ao cumprimento de normas da ABNT de acessibilidade arquitetônica, urbanística, na comunicação e informação.

Com estruturas que têm se configurado como um aglomerado de prédios com espaços repetitivos e, em geral, pouco atrativos, as construções de espaços para o ensino superior no Brasil foram marcadas por edifícios que:

Independentemente de suas qualidades arquitetônicas exteriores, à medida que eram concluídos já estavam longe de poder cumprir suas funções frente às renovações curriculares, às dinâmicas atualizadas de ensino e pesquisa e às novas tecnologias de apoio didático que iam surgindo. Reformas e adaptações foram e ainda são as alternativas possíveis, porém, dispendiosas, para tentar amainar problemas e permitir que as atividades possam ter continuidade (PINTO; BUFFA, 2009, p. 65).

Sabemos que a despeito da legislação nacional voltada à acessibilidade física, as IES do país possuem ainda uma estrutura ineficiente.

Muitas edificações, apesar de serem bastante sofisticadas, arrojadas e modernas, não incluem na sua construção soluções que considerem os diversos tipos de usuários, inclusive as pessoas portadoras de deficiência, tornando o acesso e a movimentação dessas pessoas bastante difícil e, em certos casos, até impossível (LEITE, 2007, p. 178).

Não obstante às soluções de acessibilidade atenderem a esta demanda da população (Pessoas com deficiência), tais iniciativas podem beneficiar uma gama de pessoas no afã de participar em igualdade de oportunidades das mesmas atividades a que todos os sujeitos com/sem deficiência podem/deveriam ter acesso. Todavia, ressaltamos que o Decreto deveria negar medidas de atendimento exclusivo ou segregadoras, considerando os espaços como universais.

Destacamos que a introdução do desenho universal no Decreto representa enorme passo para a construção de uma perspectiva inclusiva na legislação nacional. No documento, não apenas é regulamentado que as construções devem obedecer aos princípios da universalidade dos espaços como também são fomentadas as ações no campo do currículo da educação superior e reconhecimento da importância das pesquisas acerca do desneho universal.

A respeito de investimentos para construções acessíveis, Sassaki (2010, p.35) alerta "Mas, a preocupação da universidade em adaptar seus ambientes físicos tem sido tão tímida quanto a preocupação em adaptar o acesso ao currículo e em preparar os professores dos cursos superiores." Nesse sentido, o Decreto abre caminhos para o fortalecimento do debate acerca do 
desenho universal e seus dedobramentos práticos.

No Decreto 6.949/09 que promulga a Convenção Internacional sobre os Direitos das Pessoas com Deficiência e seu protocolo facultativo, a acessibilidade é compreendida como conjunto de medidas para assegurar às Pessoas com deficiência o acesso, em igualdade de oportunidades com as demais pessoas, ao meio físico, transportes, à informação e comunicação entre outros serviços e instalações, com eliminação de obstáculos à acessibilidade.

Entre as definições do art. $2^{\circ}$, salientamos as de "adaptação razoável" e "desenho universal". Este é definido como concepção de produtos, ambientes, programas e serviços usados, na medida do possível, por todas as pessoas, sem adaptações ou projetos específicos, considerando, porém, a utilização de ajudas técnicas. Já “adaptação razoável” é entendida como modificação/ajuste que não acarrete ônus indevido, quando requerida individualmente. (BRASIL, 2009)

A acessibilidade é tratada no art. $9^{\circ}$ enquanto acesso em igualdade de oportunidades com as demais pessoas, ao meio físico, transporte, informação e comunicação, com eliminação de barreiras. Elucida o texto que os Estados Parte deverão implementar medidas de acessibilidade, incluindo formação em relação ao tema, assegurando liberdade, igualdade de oportunidade, mobilidade pessoal, vida independente e inclusão da Pessoa com deficiência.

O direito das Pessoas com deficiência à educação coube ao art. 24. Os Estados - Parte reconhecem o direito dessas Pessoas à educação em todos os níveis e assegurarão que nenhuma pessoa seja excluída do sistema educacional sob alegação de sua deficiência. Para tanto, medidas de apoio individualizadas serão tomadas em ambientes que maximizem o desenvolvimento social e acadêmico. O acesso à educação no ensino superior é garantido mediante "adaptações razoáveis" para Pessoas com deficiência.

Em todo o corpo do texto o Decreto escreve sobre acessibilidade no sentido de garantir à Pessoa com deficiência o uso dos espaços e equipamentos com autonomia, uma vez que o próprio documento trata dos direitos dessas Pessoas.

Apesar de considerar a possibilidade de ajudas técnicas específicas para Pessoas com deficiência, o documento traz à baila a importância do desenho universal o que aponta uma tentativa de inclusividade, uma ideia de construções acessíveis a todos. A eliminação de obstáculos e barreiras à acessibilidade que serão aplicadas a edifícios de uso público aparece de maneira tímida com intuito de garantir igualdade de oportunidades. Esse Decreto marca a entrada dos direitos das Pessoas com deficiência na Constituição ao adquirir status de Emenda Constitucional. Nenhum documento antes desse Decreto recebeu status semelhante na história brasileira. 
Temos dito que barreiras nas edificações obstaculizam o acesso físico ao espaço, o que dificulta ou impede a experiência de estar e acessar ao conhecimento garantido nesse lugar. Essa impossibilidade criada pela ausência de estrutura gera a insatisfação nos espaços e inviabiliza a identificação do sujeito com o meio físico.

É salutar que a legislação brasileira vise a promoção da inclusão da Pessoa com deficiência no ensino supeior por meio da acessibilidade física. Porém, acreditamos nefasta a preocupação no atendimento exclusivo a essas Pessoas, e, no caso das IES, dos estudantes com deficiência. Parece-nos um retrocesso vislumbrar a acessibilidade para benefício de um grupo exclusivo, sendo que os espaços públicos, como as Universidades, são utilizados por diversas pessoas.

O Decreto 7.611/11 (BRASIL, 2011) ao tratar da educação especial e do atendimento educacional especializado, afirma no art. $1^{\circ}$ o dever do Estado na garantia de um sistema educacional inclusivo em todos os níveis, com igualdade de oportunidades. Também escreve sobre a não exclusão do sistema sob alegação de deficiência e a adoção de medidas individualizadas em ambientes que maximizem o desenvolvimento acadêmico e social, ratificando o texto do Decreto 6.949 (BRASIL, 2009).

Os recursos de acessibilidade previstos no Decreto 7.611 são pertencentes ao atendimento educacional especializado, organizados institucional e continuamente, o qual deve assegurar condições de progressão nos estudos em níveis, etapas e modalidades de ensino. Para tanto, a União prestará apoio junto aos Estados e Municípios para, entre outras ações, promover:

\footnotetext{
V- adequação arquitetônica de prédios escolares para acessibilidade;

VI- elaboração, produção e distribuição de recursos educacionais de acessibilidade; e

VII- estruturação de núcleos de acessibilidade nas instituições federais de ensino superior

(...)

$\S 5^{\circ}$ Os núcleos de acessibilidade nas instituições federais de educação superior visam eliminar barreiras físicas, de comunicação e de informação que restringem a participação e o desenvolvimento acadêmico e social de estudantes com deficiência (BRASIL, 2011).
}

O Decreto impulsiona mais um movimento positivo na legislação quando institui os núcleos de acessibilidade pois apesar de concebermos que auxílios advindos de construções acessíveis amparam as mais diversas formas humanas, a acessibilidade tem sido luta daqueles que se dedicam à inclusão da Pessoa com deficiência. Essa conquista é tão importante quanto necessária, pois a partir podemos pensar nessas Pessoas tomando espaços importantes, como a educação.

Apontando algumas dificuldades para o acesso e permanência do Estudante com 


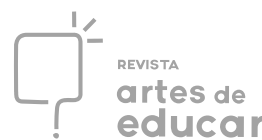

deficiência na universidade, Miranda (2011) destaca a escassa destinação de verbas para adaptações físicas e contratação de recursos humanos especializados e capacitados, além da revisão nos currículos para que contemplem conteúdos específicos para os futuros profissionais inclusivos. Aliada a esses fatores está a "própria história de exclusão, peculiar à educação superior no país, com forte tendência à privatização, ao elitismo, como também ao mito de incapacidade creditado à pessoa com deficiência” (MIRANDA, 2011, p. 120)

Partindo da premissa da universidade que tem papel articulador no ensino, pesquisa e extensão, e de que seus portões, bibliotecas, salas de aula, grupos de pesquisa, hospitais universitários e outros espaços de atendimento à comunidade precisam ser acessíveis fisicamente a todo aquele que nele desejar entrar, entendemos que sua estrutura física deve ser inclusiva.

\footnotetext{
Atualmente, há uma grande preocupação com a diversidade das características individuais da comunidade universitária e se considera fundamental responder efetivamente aos anseios dessas pessoas por meio da implantação de mecanismos de atuação voltados aos tipos de necessidades especiais. Trata-se de uma política social e não mais compensatória, mas de direito à cidadania (MIRANDA, 2011, p. 129).
}

Em estudo sobre acessibilidade no ensino superior, Duarte e Cohen (2004, p.2) explicam que "Pode-se considerar que, quando um único aluno for impedido de entrar numa biblioteca ou numa sala de aula pela simples existência de uma barreira física, a função educadora de uma Universidade estará sendo colocada imediatamente em xeque."

Afirmamos que os núcleos de acessibilidade introduzidos no Decreto representam pólos de apoio e de disseminação da importância do acesso físico aos espaços do ensino superior. Certamente que a presença de Estudantes com deficiência nos ambientes não será garantia de uma sociedade inclusiva, entretanto, é o fato de estar lá, de inaugurar a presença dessas pessoas, professores, estudantes, funcionários e comunidade, que se fomentará ainda mais o debate entorno do acesso para todos.

O decreto tem apresentado um esforço no sentido de garantir o direito da Pessoa com deficiência ao uso do espaço do ensino superior. Contudo, observamos que a legislação busca a eliminação de barreiras numa perspectiva ainda excludente, pois abriga a ideia de acessibilidade de física para Pessoas com deficiência.

\section{Reflexões finais}

Nessa pesquisa analisamos sob qual abordagem a legislação nacional tem se deslocado no que concerne à acessibilidade física no ensino superior, sem a qual não há acesso e permanência 
do Estudante com deficiência.

Sabemos que a acessibilidade teve início pela luta de Pessoas com deficiência e por grupos que lutam em defesa dos direitos desses Sujeitos. Também não ocultamos a importância que a acessibilidade física tem para o ingresso e permanência de Estudantes com deficiência no ensino superior.

Entendemos que a presença física da Pessoa com deficiência no ensino superior será profícua na medida em que enseje debate, ação e reflexão. Caso contrário, promoverá apenas uma inserção física da pessoa nos ambientes, sem problematizar, entretanto, a estrutura social e cultural que permeia a construção dos espaços (LOCH, 2007).

Portanto, proporcionar a participação plena do Estudante com deficiência no ensino superior vem problematizar a questão do acesso, do currículo, das relações entre pessoas com e sem deficiência, da formação de professores, entre outras discussões que germinam na dialética inclusão/exclusão. Entre outras discussões levantadas, problematizamos a estandardização espaços e afirmamos que há uma multiplicidade de formas de apreensão e atenção às especificidades que influenciam as diferentes maneiras de experienciar os espaços. Isso nos faz pensar que os ambientes poderiam ser planejados a partir da ideia de diversidade humana mas o que tem prevalecido é a ideia da existência do homem-padrão como referencial.

Pensando nesses diferentes elementos a serem considerados na construção dos espaços, começamos a questionar sobre a intencionalidade das construções e modo de apreensão das pessoas nos espaços físicos, seus diferentes ângulos de visão, deslocamentos e relações pessoais de lugar/espaço.

Consideramos que os avanços trazidos pela legislação nacional na regulamentação da acessibilidade física nas edificações de uso público, incluindo as instituições de ensino superior, podem beneficar não somente Estudantes com deficiência mas todos os demais usuários dessas instalações.

Para análise dos textos da legislação brasileira, partimos de uma abordagem inclusiva na qual cabe falar em espaços que pensem em equiparação de oportunidades, em construções que busquem agregar a maior gama antropométrica possível, ou seja, estruturas físicas para Pessoas com e sem deficiência.

Todavia, levantamos o questionamento de que as construções não devem ser pensadas para um grupo exclusivo, não devem ser projetadas ou reformadas com o objetivo de atender uma demanda específica. Esse caráter de exclusividade é observado em todo o texto da legislação nacional que visa garantir espaços mais acessíveis.

Sabemos que, mesmo após a conquista de direitos legais expressos na legislação 
brasileira voltados à acessibilidade física ensino superior, há muito a superar. Estamos com Diniz (2012, p. 69) quando escreve que "Há desigualdades de poder que não serão resolvidas por ajustes arquitetônicos" mas também acrescentamos que a eliminação de barreiras garantida pela legislação representa avanços, ainda que no bojo dos documentos legais percebamos não percebamos uma abordagem inclusiva na concepção dos ambientes físicos.

\section{Referências}

ASSOCIAÇÃO BRASILEIRA DE NORMAS TÉCNICAS. NBR 9050. Norma Brasileira Registrada $n^{o} 9050$ de 2004. Disponível em: http://www.abnt.org.br. Acesso em: 04 mai. 2012.

BRASIL. Constituição da República Federativa do Brasil de 1988. Brasília, DF. Disponível em: https://legislacao.planalto.gov.br/legisla/legislacao.nsf/viwTodos. Acesso em 10 jun. 2017.

. Decreto $n^{\circ} 3.956$ de 8 de outubro de 2001. Diário Oficial da União. Brasília, DF. Disponível em: http://legislacao.planalto.gov.br/legisla/legislacao.nsf/Viw_Identificacao. Acesso em 23 jun. 2017.

. Decreto $n^{o} 5.296$ de 2 de dezembro de 2004. Diário Oficial da União. Brasília, DF. Disponível em: http://legislacao.planalto.gov.br/legisla/legislacao.nsf. Acesso em 4 jun. 2017.

Decreto $n^{\circ}$ 6. 949 de 25 de agosto de 2009. Diário Oficial da União. Brasília, DF. Disponível em: http://legislacao.planalto.gov.br/legisla/legislacao.nsf/Viw_Identificacao. Acesso em 11 jul. 2017.

. Decreto $n^{\circ} 7.611$ de 17 de novembro de 2011. Diário Oficial da União. Brasília, DF. Disponível em: http://legislacao.planalto.gov.br/legisla/legislacao.nsf. Acesso em 24 jun. 2017.

. Portaria $n^{\circ} 3284$ de 07 de novembro de 2003. Diário Oficial da União. Brasília, DF. Disponível em: http://portal.mec.gov.br/seesp/arquivos/pdf/port3284.pdf. Acesso em 11 jul. 2017.

CARVALHO, Rosita Edler. Escola Inclusiva: a reorganização do trabalho pedagógico. 5 ed. Porto Alegre: Mediação, 2012.

CHIZZOTTI, Antonio. Pesquisa em ciências humanas e sociais. São Paulo: Cortez, 2008.

DINIZ, Débora. O que é deficiência. São Paulo: Brasiliense, 2012.

DISCHINGER, Marta; PADARATZ, Rejane; ELY, Vera Helena M. B. Acessibilidade e inclusão no ensino para melhoria da qualidade de vida urbana. Florianópolis, SC. 2005.

DUARTE, Cristiane Rose de Siqueira ; COHEN, Regina. Acessibilidade aos Espaços do Ensino e Pesquisa: Desenho Universal na UFRJ - Possível ou Utópico? In: NUTAU 2004: Demandas Sociais, Inovações Tecnológicas e a Cidade, 2004, São Paulo. Anais NUTAU 2004: Demandas Sociais,Inovações Tecnológicas e a Cidade, 2004. 
Turismo para todos: metodologia para confecção de uma guia do Brasil acessível. In: TUNES, Elizabeth; BARTHOLO, Roberto. (orgs.). Nos limites da ação: Preconceito, inclusão e deficiência. São Carlos: EdUFSCar, 2007.

FÁVERO, Osmar. A Educação nas Constituintes Brasileiras. 1823-1988. Campinas, São Paulo: Autores Associados, 2001.

FERREIRA, Aurélio Buarque de Holanda. Miniaurélio Século XXI Escolar: O minidiconário da língua portuguesa. $4^{\mathrm{a}}$ ed. rev. e ampliada. Rio de Janeiro: Nova Fronteira, 2001.

FORTUNA, Juliana . O conceito de acessibilidade e suas relações com a educação e cidadania. Criciúma : Ed. do Autor, 2009. Disponível em: http://capes.gov.br/servicos/banco-de-teses. Acesso em: 06 mai. de 2012.

INSTITUTO BRASILEIRO DE GEOGRAFIA E ESTATÍSTICA. Censo Demográfico 2010. Resultados Preliminares da Amostra. Brasília, 2011. Disponível em http://www.ibge.gov.br/home/. Acesso em 19 jul. 2017.

LEITE, Flávia Piva Almeida. O município acessível à pessoa portadora de deficiência: o direito à eliminação das barreiras arquitetônicas. São Paulo: RCS Editora, 2007.

MAZZONI, Alberto Angel. Deficiência X Participação: um desafio para as universidades. Tese. 2003. Disponível em: http://www.ufsc.br. Acesso em 20 mai. 2017.

MIRANDA, Theresinha Guimarães. A inclusão de pessoas com deficiência na universidade. In: JESUS, Denise Meyrelles de. et. al. (orgs.) Inclusão, Práticas Pedagógicas e Trajetórias de Pesquisa. 3 ed.Porto Alegre: Mediação, 2011.

SANTOS FILHO, Gildo Magalhães dos. Construindo um itinerário histórico do desenho universal: a normatização nacional e internacional da acessibilidade. In: PRADO, Adriana R. de Almeida; LOPES, Maria Elisabete; ORNSTEIN, Sheila Walbe. (orgs.) Desenho Universal: caminhos da acessibilidade no Brasil.São Paulo: Annablume, 2010.

MARTINS, Lúcia de Araújo Ramos. Identidade, diversidade e inclusão. In: FORMAÇÃO DO PESQUISADOR EM EDUCAÇÃO: identidade, diversidade, inclusão e juventude. PIZZI, Laura Cristina Vieira; FUMES, Neiza de Lourdes Frederico (orgs.). Maceió: EDUFAL, 2007.

PINTO, Gelson de Almeida; BUFFA, Ester. Arquitetura e Educação: câmpus universitários brasileiros São Carlos: EdUFScar, 2009.

SASSAKI, Romeu Kazumi. Inclusão: Construindo uma sociedade para todos. $8^{\mathrm{a}}$ ed. Rio de Janeiro(RJ): WVA, 2010.

LOCH, Márcia do Valle Pereira. Convergência entre Acessibilidade Espacial Escolar, Pedagogia Construtivista e Escola Inclusiva. Tese (Doutorado em Engenharia de Produção). Universidade Federal de Santa Catarina, Programa de Pós-Graduação em Engenharia de Produção, Florianópolis, 2007. 


\footnotetext{
${ }^{\text {i }}$ Doutorada do Programa de Pós-graduação em Educação da Universidade do Estado de Santa Catarina (PPGE/UDESC).

ii Professor Associado do Programa de Pós-graduação em Currículo e Gestão da Escola Básica da Universidade Federal do Pará (PPEB/UFPA)

iii Professor Titular do Programa de Pós-graduação em Educação da Universidade do estado de Santa Catarina (PPGE/UDESC)
} 